\title{
ARBORIZAÇÃO VERMELHA E O CAOS
}

\author{
Matheus Maramaldo Andrade Silva ${ }^{1}$ \\ mmaramaldo@gmail.com
}

"Enquanto as ideias florescem com todas suas belezas, a Revolução surge com espinhos e espadas até esbarrar na peste disseminada como pólvora."

Matheus Maramaldo

O autor de 15/10 - Arborização Vermelha e o Caos possui uma tendência esquerdista, marxista, trotskista, leninista, melhor afirmar: sem decisão ainda, e ao mesmo tempo cristã e católica. Raciocinar em tamanha confusão é uma grande fonte de inspiração para refletir sobre o cotidiano e a história, a exemplo desta série.

Como analisar de forma crítica os seus próprios conceitos? Suas próprias ideologias? De alguma forma, ver o Comunismo e sua aplicação não é ver uma história linda, e sim a corrupção dos homens frente a um embasamento coerente e racional. Esta série é uma apologia cheia de pregos nos sapatos quanto aos grandes nomes da esquerda pensante, guerreira... e quanto a intelectualmente deficiente. É uma visão de quem busca explicitar quem considera ser os mocinhos e os vilões para o público.

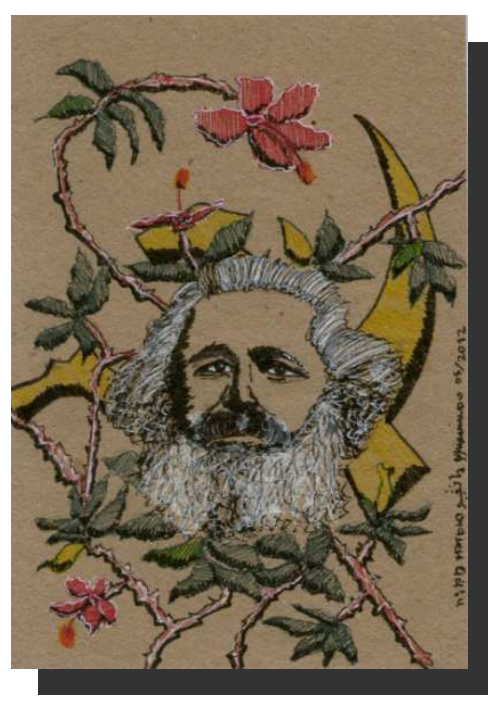

Figura 1 - Chá de Hibisco, M. M. (2012) (Fonte: Autor)

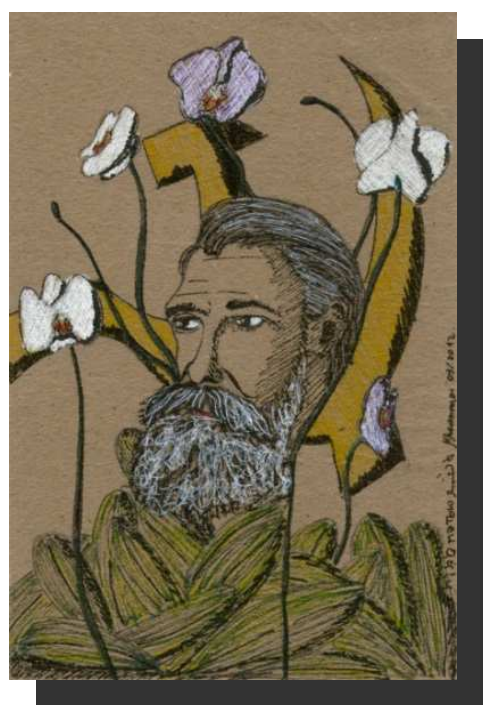

Figura 2 - Vaso com Orquídeas, M. M. (2012) (Fonte: Autor)

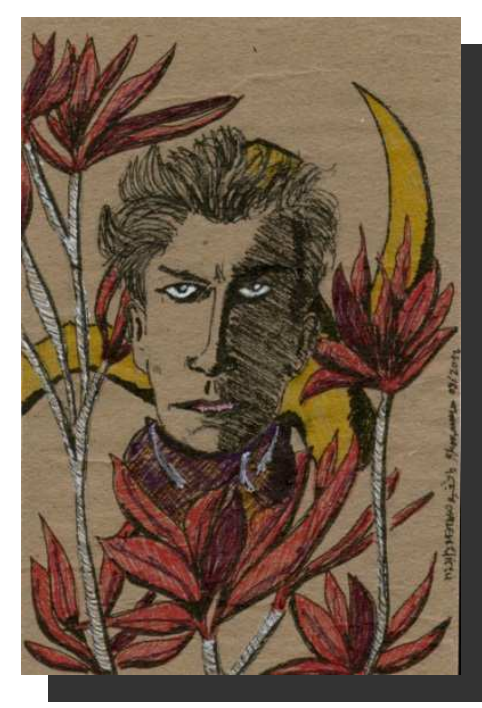

Figura 3 - Cordiline Fogo, M. M. (2012) (Fonte: Autor)

\footnotetext{
${ }^{1}$ Graduando da Arquitetura e Urbanismo pela Universidade de Brasília
} 
Olhando para trás, estávamos realmente preparados para a Revolução? O mundo hoje tenta reformular os preceitos marxistas a todo o momento, mas todos sabem que uma blitzkrieg armada não é mais a solução para o início de um mundo melhor. Naquele período, estávamos inspirados pela mudança; pela superação de czarismos e modelos demasiadamente exploradores, em níveis não aceitáveis nem para as ditaduras contemporâneas, mas desprovidos da consciência política necessária, o que justificava, de certa forma, o que ocorreu.

Essa Revolução, como o Comunismo, teve uma história, uma linha de pensamento com teoria, intenção e aplicação, e esta série trata com diversos elementos de revelar-nos.

Partindo mais diretamente para as gravuras, não podemos afirmar muita coisa acerca das obras ao notar algo de importante nas escolhas de material. São desenhos feitos em papel pardo com canetas hidrográficas, nanquim e canetas de gel. Contudo, fica claro que o autor queria, ao esboçar estas imagens, fazer o observador entender, de forma direta, o que estava sendo exposto, ao menos a parte literal.

Esses desenhos possuem uma estrutura composta de três elementos: o retrato, o símbolo comunista e a vegetação. Conforme vamos passando pelas imagens, o que se vê é uma concordância entre a vegetação escolhida e o personagem retratado. O autor quer que você leia aquilo como um vitral de igrejas, aqueles que contam a história de Jesus, limitando-se aqui à história do pensamento comunista.

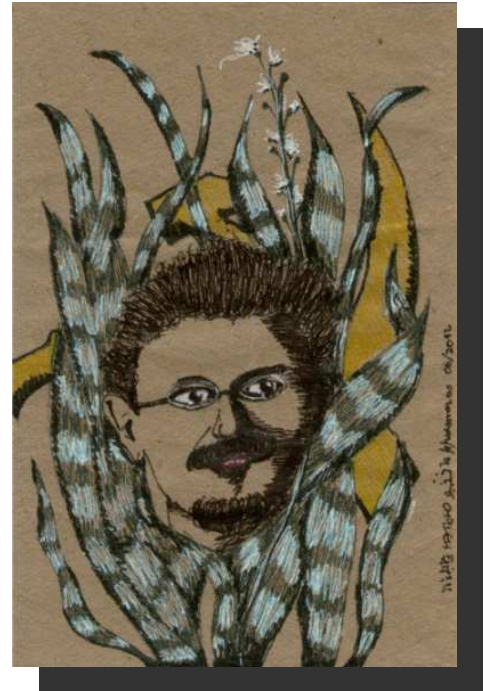

Figura 4 - Invasão de Sanseverias, $M$. M. (2012) (Fonte: Autor)

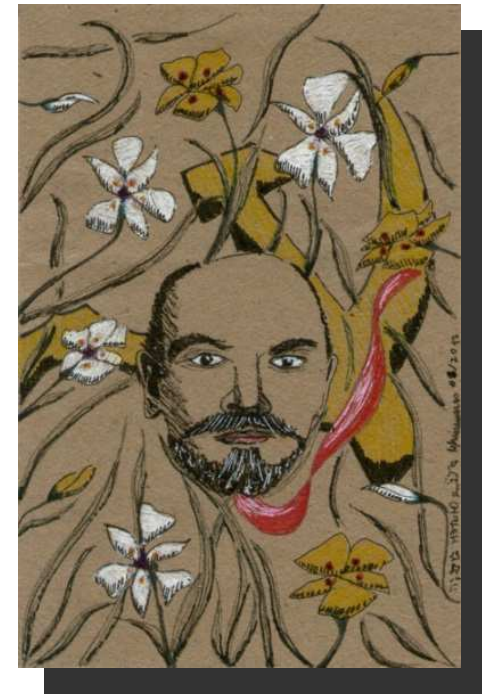

Figura 5 - Moréias, M.M. (2012) (Fonte: Autor) 
O retrato nos convence, normalmente, que aquele que está sendo exposto é importante. É uma imagem austera, forte, simples. Mas, estando com flores e um símbolo, perde sua imponência reveladora, pelo menos neste caso, pois, o que está atrás e ao lado é mais importante do que a própria imagem. Estes elementos são as qualificações da pureza da foto, algo bem mais difícil em um retrato comum.

O olhar seria importante? Embora o autor ame explorar os significados que os olhos podem ter, eles, aqui, estão em um segundo plano. O olhar está direcionado para o retratista, é uma pose comum e em poucos casos revela a alma.

O símbolo é de rápida compreensão. Ele confirma e credencia todo o romance. Quando se desenha uma placa de trânsito, o que se quer é que o motorista entenda facilmente. A foice com o martelo juntos tem este objetivo na obra - não é a narrativa do capitalismo.

Antes de partir para maiores especificidades, cabe falar de um último elemento a vegetação. Ela é o destaque deste conjunto de gravuras. Diz tratar-se de um herói, se este está sendo debochado, se é inocente, ou se é chama. As plantas são a própria história e poderiam estar sem o símbolo ou sem o retrato, bastando o título ser suficiente.

Logo, o que há em cada imagem? A série começa com os dois pilares da teoria: Marx e Engels. Eles são retratados junto a flores bonitas, chamativas, mas ainda dóceis. Marx, como um profundo radical de suas ideias, mas um tanto afastado da Revolução, por ainda estar no início de todo o processo, é retratado junto a hibiscos, que, apesar de terem ramos visualmente perigosos, só exibem corcundas inofensivas e flores belíssimas. Os hibiscos são "o mimo de Vênus", a suavidade e um ótimo verão - e teorias são presentes e enquanto papel são ainda muito diferentes de armas, mas prenúncios fortes do que virá pela frente.

Engels, teórico menos conhecido, mas, não menos importante, dá mais liga à amálgama do pensamento marxista. Ele está posto próximo a orquídeas, flores mais singelas do que os hibiscos, mas similarmente belas. As orquídeas são frágeis e reforçam a ideia da fraqueza das teorias frente à realidade. Um vaso tem de ser cuidado, merecendo carícias próprias para cada planta ali crescendo. As teorias não merecem o mesmo tratamento?

Estas primeiras imagens não trazem radicalidade, mas, a apresentação de uma ideia nascente e ainda meiga. 


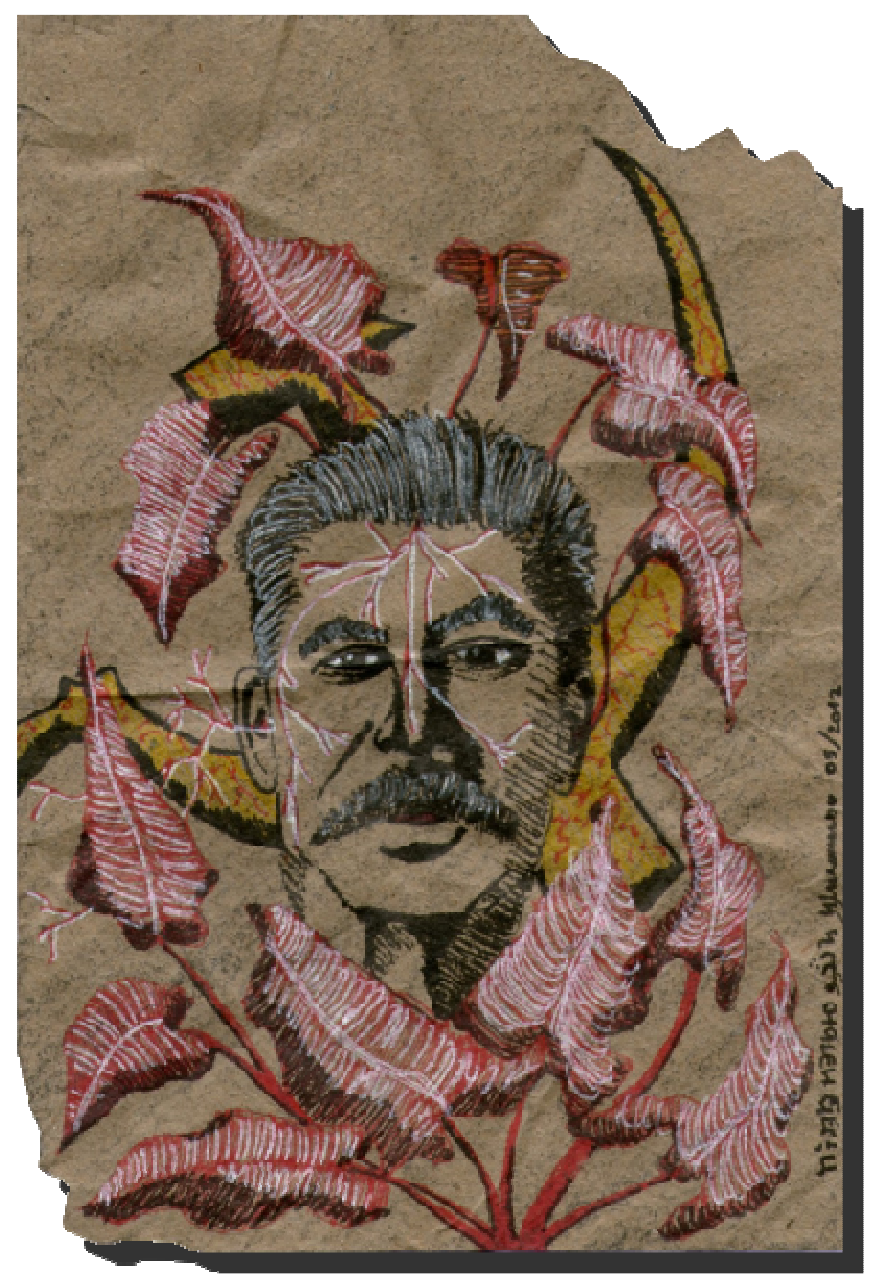

Figura 6 - Os filodendros chegam ao Ural, M.M. (2012) (Fonte: Autor)

A segunda parte da leva retrata Maiakovski, Trotsky e Lênin. Quem são eles? Os verdadeiros revolucionários, os que usaram da teoria e foram à rua, ao campo, ao palácio defendê-la. A vegetação que os representam já não possui inocência ou docilidade, é mais intempestiva, agressiva.

Maiakovski é representado junto a cordilines. Poeta da Revolução, pertencente à massa das pequenas e grandes guerras da Praça Vermelha, escrevia com tal medida e exagero. As cordilines não são flores, são rústicas, vermelhas em um tom sanguíneo e suas folhas são lanceoladas, vibrantes, como o pensamento do poeta. A figura parece dizer que algo tenso e desproporcional está próximo de acontecer. Talvez, seja a única gravura em que o retrato mostre um olhar fixo e tão forte quanto à vegetação.

Já na imagem com Trotsky, ele está abarrotado de espadas de São Jorge. Guerreiro, defendia a Revolução Internacional, estava na linha de frente e tinha uma postura firme. Nada melhor do que pontas agudas para estar junto dele. A figura conta com sanseverias, de formato de espada, são invasoras em clima e campo apropriados, 
venenosas (...) soldados em ascensão. As espadas de São Jorge são ainda purificadoras espirituais e neutralizadoras de energias negativas segundo a crença popular, nada mais justo para um idealista morto em pleno exílio.

Lênin é um caso mais complicado, pois, ao mesmo tempo que participa da Revolução, fica com o poder. Estaríamos perto do fim? Radical, convicto das ideias revolucionárias, está cercado ainda por vegetação sagaz, seja pela beleza ou pela força. São flores diferentes das vistas em Marx e Engels, são secas e austeras. As moreias são flores resistentes, de folhagem dura e pontuda, selvagens. Moreias ainda estão no patamar animal e mitológico - são serpentes marinhas e têm toda uma história de dissimulação, envolvência e violência. O poder muda vários paradigmas na política.

A série termina com o desenho mais simbólico e que tem os pontos mais importantes a serem discutidos. Stálin está ali retratado junto a filodendros.

A gravura não está mostrando mais uma cena heroica ou revelando uma qualidade do personagem. Stálin está sendo sugado pela planta, a folha está sendo dominada pelos filodendros. O símbolo puro e amarelo do comunismo, atrás de todas as figuras, está agora sendo apreendido pelas raízes da vegetação. Nesta imagem, o material é mais revelador, pois está amassado e carcomido nas pontas. O autor está informando que aquilo já é a ruína de todo um trabalho, de toda uma ideia, quando um traidor chega ao poder.

Em todas as imagens, o retrato é como de uma foto, em que o personagem olha fixamente para a câmera ou faz uma pose. Eles estão firmes e imóveis. Porém, em $O s$ filodendros chegam ao Ural, a vegetação tende a querer apagar o retrato, como se agora tudo de bom fosse passado.

Filodendros são trepadeiras vorazes das sombras que asfixiam a planta suporte. Suas folhas são belas, mas suas raízes são predatórias. A planta não diz sobre a personalidade do retratado, diz o que houve com ele, o que houve com toda aquela teoria e o que poderia ser feito com o ditador.

Após observar todos estes desenhos, fica a ideia de narrativa e de idolatria. $\mathrm{O}$ autor quer mostrar sua afeição pelo comunismo e sua história. Contudo, seu enredo tem final. Após a beleza e as obras construídas dos primeiros heróis, chega ao mundo alguém que destrói toda a novela. É esta uma crítica ao olhar cego quanto à política também.

Lendo hoje sobre tal ideologia, parece terra arrasada. O mundo não vê mais aplicações e julgam perante os erros ditatoriais da história acima. Mas, há todo um 
processo de releitura, feito por vários sociólogos e cientistas políticos, que enxergam futuro no marxismo, ou em partes desse. Países escandinavos são exemplares cada vez mais ao aplicarem medidas que beneficiam o povo como um todo, trazendo pouquíssimo prejuízo ao estado - boa mobilidade urbana, energia limpa, programas sustentáveis de aposentadoria - isso é socialdemocracia que, por que não, pode se tornar uma vivência livre da necessidade de compra e venda.

Além de práticas de bem estar social, muitos teóricos enxergam que é inevitável ingressar em geração de compartilhamento e de solidariedade, em vez de barganha. José Arthur Giannotti escreve em seu prefácio do livro Marx, além do marxismo que "Nosso desafio é impedir essa continuidade, por conseguinte, dar liberdade suficiente para que os agentes marquem os preços de seus produtos, sem que sejam levados pelo automatismo de um sistema produtivo, que se transforma em um robô visando produzir e acumular riquezas em vista da simples acumulação.”. Estamos muito presos às novas tecnologias e no fato de termos que acumular o máximo que podemos de capital. As pessoas existem e precisamos nos relacionar de outra forma com elas além do interesse.

O comunismo, o socialismo e todas as doutrinas e ideologias desta vertente ainda são plausíveis, pois há uma grande gama de atribuições e aplicações em nosso cotidiano de grande parte dos textos marxistas. Devemos progredir nessa discussão, visto que toda a história tem fatos e versões. Aqui, o autor construiu uma reflexão sobre sua própria verdade frente ao que é para ele o comunismo e sua realidade, e quis transmiti-la de alguma forma ao observador. Foi com flores e retratos.

\section{REFEREÊNCIAS BIBLIOGRAFICAS}

SAMPAIO, Plínio Arruda (org.), Desafios da luta pelo socialismo, Expressão Popular, 2002.

GIANNOTTI, José Arthur, Marx além do Marxismo, L \& PM, Porto Alegre, 2009.

LEFEBVRE, Henri, Marxismo, L \& PM, Porto Alegre, 2010.

MARX, Karl e ENGLES, Friedrich, Manifesto do Partido Comunista - 1848, L \& PM, Porto Alegre, 2009.

SILVA, Matheus Maramaldo Andrade Silva, [S.I.]: O Padre Húngaro, O Maiakovski que queria ser, Brasília, 2011. Disponível em:

<https://docs.google.com/file/d/0B7fdSRuIdn

KkeGZMaVBBOUFxWU0/edit?usp=sharing>. Acesso em: 25 de agosto. 2013. 